\title{
İșletme ve Kümelerde Stratejinin Önemi ve Komşu Alan Stratejik Yaklaşımı
}

\author{
Çağrı BACAK \\ Sorumlu Yazar, Sanayi ve Teknoloji Bakanliğ \\ cagribacak@gmail.com,ORCID:0000-0001-5553-8092 \\ Bekir Tolga ARICAN \\ Sanayi ve Teknoloji Bakanlı̆̆
}

\section{$\ddot{O} z$}

Günümüz ekonomisinin şiddetli değişim ortamında gelecekte var olabilmenin tek yolu stratejik düşüncedir. İşletmelerin karlı büyümelerini devam ettirebilmeleri faaliyette bulundukları ekosistemi iyi tanımalarına bağlıdır. Firmalar, geleneksel endüstri analizlerinden ziyade içinde bulundukları ekosistemleri analiz ederek yeni ve komşu alanlarda yatııım firsatları bulmaktadır. $\mathrm{Bu}$ anlamda, yeni alanlara sıçramak isteyen işletmeler için strateji dinamiklerinin ortaya konulması ve açıklanması önemlidir. Bu çalışmada, strateji kavramı tarihsel olarak açıklanmış, yönetim guruları tarafindan ortaya atılan tezler tartışılmıştır. Komşu alan stratejisi ayrıntılı şekilde ele alınarak, stratejinin dinamikleri işletmelerde olduğu gibi kümelenme girişimleri için de açıklanmıştır. Çalışmanın en önemli sonucu, işletme stratejisinin dinamiklerinin işletmenin içinde bulunduğu ekosistem, diğer bir ifadeyle kümeyle ilgili olduğudur. $\mathrm{Bu}$ kapsamda, politika yapıcıların dinamikleri iyi analiz ederek destek mekanizmasını tasarlaması gerekmektedir.

Anahtar kelimeler: strateji, rekabet gücü, kümelenme, komşu alan stratejisi

Jel Kodu: L10, M10

Importance of Strategy in Firms and Clusters and Strategic Approach of Adjacency Move ${ }^{1}$

\begin{abstract}
The only way for firms to survive in an economic environment of change is strategic thinking. Sustaining a profitable growth for companies depends on the ability of understanding the ecosystem in which they exist. Firms find investment opportunities in new and adjacent areas by analyzing the ecosystem rather than any other traditional industrial analysis. In this respect, for firms seeking for leap frog into new areas, it is important to reveal the strategy with its dynamics. In this study, the evolution of strategy concept has historicaly been explained, the thesis put by management gurus have been discussed. Adjacency strategy has been analyzed and Dynamics has been put forward for clusters as of in firms. The most striking result of this study is that, Dynamics of the firm strategy are based on the ecosystem, in other words on the cluster in which they exist. In this respect policy makers have to perform indeep analysis of the dynamics while designing the support mechanisims.
\end{abstract}

Key words: strategy, competitiveness, clustering, adjacency strategy

Jel Code: L10, M10

\footnotetext{
${ }^{1}$ Extended abstract is presented at the end of the article.
}

Geliş Tarihi (Received): 28.03.2018- Kabul Tarihi (Accepted): 18.02.2019

Atıfta bulunmak için/Cite this paper:

Bacak, Ç. ve Arıcan, B.T. (2018). İşletme ve Kümelerde Stratejinin Önemi ve Komşu Alan Stratejik Yaklaşımı. Çankırı Karatekin Üniversitesi İIBF Dergisi. 9 (1), 29-50. 


\section{Giriş}

Günümüz dünyasında işletmeler sürekli büyümek ve rekabetçi pozisyonlarını devam ettirmek için çeşitli arayışlar içerisindedir. Söz konusu arayışlar yatırım ve büyüme firsatları olarak karşımıza çıkmaktadır. Ancak birçok işletme yatırım ve büyüme fırsatlarını karlı bir iş birimine dönüştürmeyi başaramamaktadır. Strateji kavramının önemi bu süreçte ortaya çıkmaktadır. İşletmelerin temel işlerine (core business) ve kabiliyetlerine (capability) dayanarak geliştirdikleri büyüme stratejilerinin başarılı olması, uzmanlaştığı alanlardan uzak yatırım yapmamalarına bağlıdır. Yeni yatırım ve büyüme alanlarının (growth space); işletmelerin temel kabiliyetlerine uygun iş alanlarına komşu (adjacency) alanlarda yenilikçi iş modelleriyle olması sürekli değer yaratmanın ön koşuludur.

Türkiye'de strateji üzerine; yönetim okulu (Bakoğlu ve Özcan, 2010), insan kaynakları politikaları (Tanova ve Karadal, 2004), strateji haritaları (Berikol, 2009), stratejinin firma performansina etkisi (Akman vd., 2008; Alparslan ve Çarıkçı, 2014), strateji tipleri ve yenilik (Özşahin vd., 2017), işletme stratejisinin ihracat performansı üzerine etkisi (Kahveci, 2012), işletme yetenekleri (Papatya, 2017), işletmelerde strateji-yapı ilişkisi (Yıldırım ve Çolak, 2016) gibi başlıklarda çeşitli araştırmalar literatürde yerini almıştır. Bununla birlikte, sermaye dinamikleri ile komşu alan stratejisinin etkileşimi üzerine bugüne kadar bir çalışma yapılmamıştır. Çalışma bu yönüyle literatüre işletme ve kümelerin stratejik düşünüşünde komşu alan hareketlerinin önemi bakımından katkı sunmaktadır.

$\mathrm{Bu}$ makalenin ana amacı, stratejinin tarihsel olarak evrimini incelemek, şirket ve kümelerin stratejiyi ele alış biçimlerindeki yaklaşım farklılıkları ortaya koymak, sermaye dinamikleri ile komşu alan stratejisinin etkileşimini belirlemektir.

Bu kapsamda, ikinci bölümde strateji ve yönetim konusunda guru sayılacak birçok akademisyen ve yazarın görüşleri literatür taraması ile özetlenmiştir. Üçüncü bölümde, komşu alan stratejisi tanımı ve çeşitleri açılanmış; dördüncü bölümde ise kümelerde stratejinin dinamikleri komşu alan stratejisi kavramı ile ilişkilendirilmiştir. Kümelenme yapılarında yatırım ve büyüme stratejilerinin hangi alanlara odaklanması gerektiği açıklanmıştır. Sonuç kısmında kümeler ve politika yapıcılar için önerilere yer verilmiştir.

\section{2. İşletmelerde Strateji}

Strateji gelecek ile ilgili bir kavramdır. Strateji, işletmelerin veya organizasyonların sürdürülebilir bir şekilde faaliyet göstermesi ve rekabetçi üstünlük sağlaması için gelecekte yapması veya yapmaması gereken faaliyetlerle ilgilidir (Ülgen ve Mirze, 2007). Strateji kavramının ve işletmelere uygulamanın karışıklığı stratejinin yönetim okulları ile açıklanmasını gerekli kılmış; Sarvan ve diğerleri (2003) stratejik yönetim kavramını 10 yönetim okulu etrafında anahtar 
kavramlar ve varsayımlarla açıklamıştır (Sarvan vd, 2003). Tasarım okulu strateji teorisyenleri stratejiyi sürdürülebilir rekabet gücü üstünlüğü ile mevcut konumdan gelecekte olmak istenilen noktaya hareket olarak tanımlarken; Mintzberg bir dizi kararlar ve faaliyetler bütünü olarak tanımlamaktadır. (Ansoff, 1965; Porter, 1980; Mintzberg, 1994). Strateji gelecekte olmak istenilen noktaya ulaşmak için firmanın elindeki kaynakları sürdürülebilir rekabet gücü elde etmek üzere kullanmasıdır. Stratejiden bahsedilirken dış çevrenin de analiz edilmesi gerektiği Ansoff tarafından ifade edilmiş ve Güçlü Zayıf Yönler Fırsatlar Tehditler (GZFT) analizi işletme stratejisinde yerini almıştır (Ansoff, 1965).

Chandler (1962) stratejiyi bir işletmenin hedeflerinin ve uzun vadeli amaçlarının belirlenmesi ve buna uygun işletme kaynaklarının tahsis edilmesi olarak tanımlamaktadır. 1962 yılında yazdığı kitapta, stratejik karar süreci ile stratejik karar içeriği arasındaki farkı ortaya koyan ilk yazarlardan biri olmuştur (Chandler, 1962). İşletmelerde stratejik karar süreci stratejiyi bir faaliyetler silsilesi olarak tanımlarken stratejik karar içeriği ise işletmenin tarihsel olarak gelişiminde yaşanılan tecrübelerden ortaya çıkan bir form veya şekil olarak tanımlamaktadır. $\mathrm{Bu}$ haliyle, strateji formüle edilemeyen ancak öğrenilen bir kavramdır (Bakoğlu ve Özcan, 2010).

Ansoff, işletme stratejisi literatüründe kurumsal planlamanın öncülerindendir. GZFT analizini bir metodoloji olarak popüler hale getirmiş ve stratejik planlamayı stratejik yönetim olarak yeniden konumlandırmıştır (Ansoff, 1965). Ansoff’a göre strateji belirleme, temelde firmanın temel amaçlarına uygunluğunu tespit etmektir. Stratejinin belirlenmesi, mevcut faaliyetler ile yeni yatırım yapılan faaliyetler arasında ortak bir bağın kurulmasıdır. İşletmeler kendi uzmanlaştığı alanlara daha yakın olan alanlara yatırım yapmalıdır (Bakoğlu ve Özcan, 2010).

Ansoff'un planlı büyümesinden farklı olarak stratejik iş birimleri ve pazar payı gibi unsurlarla hareket eden Boston Consulting Group (BCG) 1970 y1lında pazar payı ve pazar büyüme ekseninde portföy yönetimi modelini geliştirmiştir. $\mathrm{Bu}$ stratejik karar modeline göre, firma sahip olduğu hangi ürün gruplarına yatırım yapılması gerektiğini ve faaliyet gösterdiği hangi alanların karlı olduğunu tespit edebilir. 


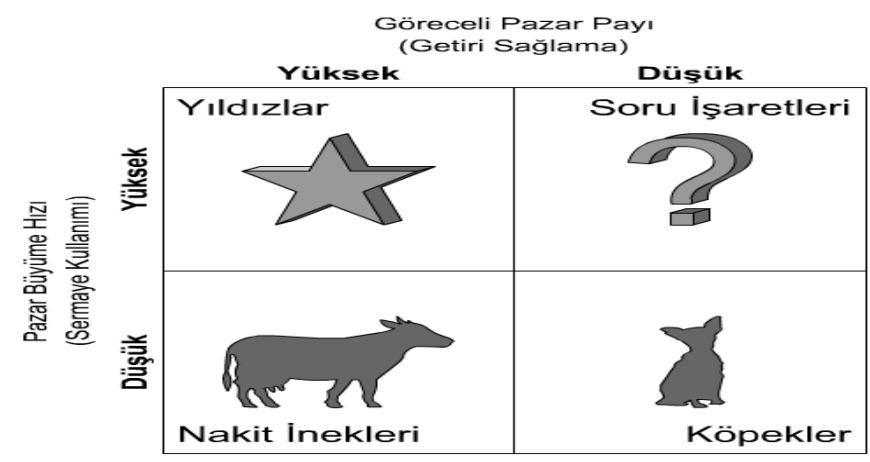

\section{Şekil 1: BCG Matrisi}

Şekil 1'e göre hem pazar payı hem de pazar büyüme hızı yüksek dilimde yer alan yıldızlar (stars) büyüyen alan olarak belirtilmektedir. "Nakit inekler" (cash cows) bölgesi olarak ifade edilen kısmen doymuş bir pazara hitap eden ürün grubudur ve yatırım ihtiyacı azdır. Hem pazar payı hem büyüme hızı düşük olan alan "köpekler" (dogs) firma ürün gruplarının kar getirmediği yatırım yapılmaması gerekli olan alanlardır. Pazar büyüme hızı yüksek olup ürünün pazar payı düşük olan alan soru işaretleri (question marks) olarak ifade edilmektedir. BCG matrisi, portföy analizi için basit bir yöntem olsa da pazar büyüme çekiciliğin, pazar payı rekabetçi pozisyonun yalnızca tek boyutunu ortaya koymaktadır Ayrıca uygulamada 2 büyük problem ile karşılaşılmaktadır. Birincisi, tanımlama hataları, bir sektör için düşük ve yüksek büyüme oranlarının veya pazar payının kolayca belirlenememesini ifade eder. İkincisi, modelin öngördüğü geçişkenlikler beklenenden kısa sürebilmektedir. Örneğin, yanlış yatırım kararları ve pazar tahminleri bir işletmenin "nakit ineklerini" beklenenden daha kısa sürede "köpeklere" dönüştürebilmektedir (Johnson vd., 2009).

Süreç içerisinde işletmeler için strateji yaklaşımının küresel boyutta ele alındığı görülmektedir. Örneğin, küresel strateji kavramını strateji literatürüne kazandıran Bartlett ve Ghoshal (1989), Managing Across Borders adlı kitaplarında uluslararası rekabet gücü elde etmek amacıyla oluşturulan küresel arenadaki stratejinin (global thinking) yerel ihtiyaçları (local act) dikkate alarak şekillenmesi gerektiğini ifade etmişlerdir. Bu düşüncenin odak noktası, çok uluslu işletmeler için stratejik seçenekleri küresel ve yerel eksende değerlendirerek olumsuz piyasa koşullarından çıkış yollarının bulunması gerektiği ortaya çıkmıştır. Bu kapsamda, yazarlar küresel strateji kavramını strateji literatürüne kazandırmışlardır (Bartlett ve Ghoshal, 1989).

Diğer yandan Mintzberg ise, işletmenin düşünce yapısıyla ilgili olarak stratejik planlamadan farklı bir süreç olduğunu ifade etmiştir. Mintzberg, öğrenme okulunun kurucusu olarak stratejinin süreç içerisinde öğrenilerek oluşacağını savunmuştur. Ona göre stratejik planlama iş planının faaliyetlere bölünmesi, bütçelenmesi, zamanlaması yani sürece dökülmesiyken; strateji, planlamadan 
önceki düşünce aşamasıdır. Mintzberg'e göre sürekli değişen ihtiyaçlar ve teknoloji yapısıyla ekosistemdeki gelişmelerin farkında olarak stratejinin belirlenmesi ancak rakiplerden daha etkili düşünce yapısına sahip olmakla mümkündür (Mintzberg, 1994).

İşletmelerde stratejik düşünceyi derinden etkileyen değişim, Porter'ın 5 güç (five forces) analizi ile olmuştur (Porter, 1991). Porter modelinde, firmaların rekabet güçlerinin 5 güç etrafında şekillendiğini ortaya koymuştur. Porter'a göre bir firmanın rekabet gücünü belirleyen beş faktör; rekabetin şiddeti, alıcıların gücü, tedarikçilerin gücü, ikame ürünler ve piyasaya yeni girenlerdir. Örneğin, faaliyet gösterilen sektörde firmanın tedarikçileri stratejik ürünlere sahipse (lityum pil, elmas vb.) karlılık tedarikçilere bağlı olacaktır. Benzer şekilde, piyasaya yeni girişler firmanın karlılığını azalttığı için firma giriş engelleri yaratarak karlılığını sürdürmeyi hedef olarak seçecektir. Porter, 5 güç analizi yapıldıktan sonra karlılık sağlayacak stratejileri belirlemiştir. Bunlardan birincisi, düşük maliyetli üretici haline gelme hedefli maliyet liderliğidir. Örneğin, Southwest Havayolları maliyet liderliği stratejisi ile sektöründe başarılı olmuştur. Müşterilerine sunduğu hızlı ve düşük maliyetli ulaşım imkanı ile geliştirdiği müşteri değer önerisini mevcut kaynaklarıyla (şehir merkezine uzak havaalanları, online satış, tek tip uçak vb.) uyumlu bir şekilde iş modeline dönüştürebilmiştir (Johnson, 2010). İkincisi ise, rakiplerden daha farklı ürün ve hizmet üreterek piyasada tutunan ve karlılığını artıran firmalar için kullanılan ürün farklılaştırmadır. Örneğin Meksikalı CEMEX, satın alma kararlarının çoğunlukla fiyat üzerinden verildiği çimento sektöründe hizmet farklılaşmasına giderek rekabetçi pozisyonunu güçlendirmiştir. Dijital teknolojileri kullanarak siparişten sonra aynı gün teslim seçeneği ile müşteri değer önerisini yeniden tanımlamıştır. Benzer şekilde Inditex Grup (Zara), bilgi iletişim teknolojilerini iş modeline entegre ederek tasarımdan satışa kadar geçen süreyi büyük ölçüde azaltarak hızlı moda iş modeli ile fark yaratmayı başarmıştır. Zara bir çok ürün gamında tasarımdan satışa kadar olan süreyi 30 günden aşağıya çekmeyi başarmıştır (Markides, 2008). Bu iki strateji, rekabet gücünü artırmak için firmalar tarafından aynı anda uygulanabilir ancak hem maliyet liderliği hem de ürün farklılaştırmanın dinamikleri ve kaynakları farklı olacaktır (Porter, 1996).

1990'lı y1llarda endüstriyel iktisat düşünce akımının geliştirdiği 5 güç analizi işletme stratejisi literatüründe geniş kabul görürken, yeni dönem stratejistleri yeni kavramlar ortaya atmıştır. Porter, rekabetçi üstünlüğün geliştirilen iki jenerik stratejiden kaynaklandığını belirtirken, farklı ve eşsiz firma içi kaynakların yeniden tanımlanması ve keşfedilmesi yoluyla rekabet gücünün sağlanacağını ifade eden yaklaşımlar geliştirilmiştir. Grant (1991) firmaların rekabet gücünün asıl kaynağının kaynak temelli (resource-based competitive advantage) olduğunu ifade etmiştir. Bu kapsamda, Grant'ın kaynak temelli rekabetçi üstünlük kavramı, Hamel ve Prahalad'in geliştirdiği temel yetkinlik kavramı ile benzeşmektedir (Grant, 1991; Hamel ve Prahalad, 1994). Gary Hamel ve C. K. Prahalad, belirli sınırları kapsayan endüstri analizinin hızlı değișen sektörlerin değer oluşturma 
süreçlerini belirlemede yetersizliğini vurgulamıştır. Hamel ve Prahalad'a göre stratejik niyet oluşturmanın temel başlangıç noktası firmanın temel yetkinliklerinin (core competency) belirlenmesidir. Temel yetkinlik, işletmenin müşterilere farklılaşmış ve taklit edilemeyen ürün veya hizmet sunmasını sağlayan bir dizi faaliyet veya beceri seti olarak tanımlanabilir (Hamel ve Prahalad, 1994). Örneğin Rynair firmasının temel yetkinliği, düşük maliyetli zihniyet (mind-set) ve operasyonel süreçleri rakiplerinden daha hızlı gerçekleştirmesidir. Vurgulanan ikinci nokta; temel yetkinliklere uygun endüstri öngörüsü (industry foresight) yapmaktır. Son olarak, stratejik niyet ile şekillendirilen endüstri öngörüsü ve plandır. Buna ek olarak, stratejide inovasyonun bir dinamik olarak ele alınması gerektiği, temel yetkinliklerin gelecekte hızla değişebileceği; rekabetçiliğin sürdürülmesi için yenilikçi yaklaşımların stratejiye hakim olması gerektiğini ifade etmişlerdir (Hamel ve Prahalad, 1994). Hamel ve Prahalad'in temel yetkinlik modeli uzun vadede stratejiyi önemsese de kısa vadede işletmelerin elde edebilecekleri faydalara ilişskin bir öneri getirememiştir.

Slywotzky’e göre firmanın temel yetkinlik analizi ile başlayan değer zinciri modeli müşteri merkezli değildir (Slywotzky, 1996). Bu bakımdan, firma tarafından müşteri gözünde bir değer oluşturma süreci müşteriyi analiz ederek başlamalı ve değişen ihtiyaçlara karşı iş dizaynı uyumlaştırılmalıdır. Müşteri merkezli bir iş dizaynı (business design) olmadan strateji geliştirme modelinin benimsenmesi nihayetinde ürün merkezli bir stratejiyi hakim kılarken günümüz rekabet ekonomisinin gereklerini yerine getirememektedir.

Grundy (1994), stratejik karar alma ile hissedar değerini ilişkilendirerek; stratejik kararların ekonomik değer üretme sürecinde karşılıklı bağımlılık ve belirsizliklerle nasıl mücadele edebileceğini ortaya koymuştur. 1998 ve 2002 yıllarında yaptığı çalışmalarla Porter'ın değer zinciri analizini, muhtemel değerleri tespit etmekten ziyade mevcut durumda değer ve maliyetleri belirlemede kullandığı için eleştirmiştir. 5 güç analizine; bir sektörde yerleşik algılar, beklentiler ve varsayımların analizini (industry mind-set) altıncı bir güç olarak eklemiştir (Grundy, 1994; Grundy, Johnson ve Scholes, 1998; 2002).

Kaplan ve Norton, stratejik uygulamalarda performans değerlendirmesi sistemi olarak özetlenebilecek "balance scorecard" modelini geliştirmiştir. Bu modelde performans ölçümleri ile yönetim fonksiyonunu daha kolay hale getirme iddiasıyla işletme performansını 4 boyutta (finansal, müşteri, iç süreçler, öğrenme ve gelişme) irdelemiştir (Kaplan ve Norton, 1992).

Peters ve Waterman (2004), üstün performans gösteren Amerikan firmaları üzerine yaptıkları yönetim araştırmasında 7S (strategy, structure, staff, skills, style, systems, shared value) modelini ortaya koymuştur. Mc Kinsey 7S modeli olarak da bilinen modelde 7 unsur sert ve yumuşak olmak üzere ikiye ayrılmıştır. Sert unsurlar, organizasyon tarafindan tanımlanması kolay ve yönetimin direk etki 
edebildiği strateji, yapı ve sistemdir. Yumuşak unsurlar ise, daha soyut kültürle ilgili olan çalışanlar, yetenekler, yönetim tarzı ve ortak değerlerdir (Peters ve Waterman, 2004). Söz konusu 7 unsur birbirini tamamladığı ve güçlendirdiği ölçüde işletmelerde başarı ortaya çıkmaktadır.

Senge, strateji literatürüne öğrenen organizasyonlar kavramı ile katkıda bulunmuştur. Organizasyonun öğrenmesi yalnızca strateji geliştirme ve uygulama aşamasında değil performans ölçümünde de etkili olmaktadır. Sistem düşüncesi (system thinking) tüm organizasyonda hakim olmalıdır. Stratejik düşünmenin üst yönetimin işi olduğu geleneksel yargısına karşı, Senge strateji belirlemenin organizasyonun her katmanında olması gerektiğini savunmuştur. (Senge, 2006).

Finkelstein, Harvey ve Lawton'a (2007) göre işletmeler, büyüme ve dönüşümlerini stratejik mükemmellik ile sağlamalı; pazar liderliği için uygulanabilecek basitlikte bir stratejiye sahip olmalıdır. Bunun için de stratejinin yanında ihtiyaçları ve amaçları doğru ifade eden bir vizyon ve vizyona ulaşmada güçlü bir liderlik gerekmektedir. Yazarlara göre strateji, işletmenin gelecekte yapacağı yatırımları ve belirleyeceği müşteri segmentleri ile ilgili iken; iş planlama, ön görülen değişikliklere cevap verme süreci olarak tanımlanmıştır (Finkelstein, Harvey ve Lawton, 2007). Böylece yazarlar stratejiyi planlamadan ayırarak liderlik ve vizyonu stratejinin olmazsa olmazları olarak görmüştür. Stratejiyi vizyon, iş modeli, değer önerisi ve uygulanan proje ve programların merkezine koymuşlardır.

Markides (2008)'e göre oyun değiştiren stratejilerin temelinde yenilikçi iş modeli yatmaktadır. Bu bakımdan yeni alan ve pazarlara yatırım yaparken geliştirilecek stratejinin merkezinde inovasyon ve yeni değer önerisi olmalıdır. Rakipler tarafından taklit edilemeyen, kopyalanamayan iş modeli inovasyonlarının stratejik inovasyon olarak değerlendirilmesi gerekmektedir. Yeni iş modelinin kopyalanmasındaki zorluk veya imkânsızlık, işletmenin var olan faaliyetlerinden farklı değer zinciri faaliyetleri içermesine bağlıdır. Böylece stratejik inovasyon, kurulu işletmelerin mevcut geleneksel iş modeli faaliyetlerinden elde edilen ürün ve hizmetlere ek özellikler ekleyerek ortaya çıkan yenilikçi ürün veya hizmetlerin müşterilerce kabul edilmesi sonucu başarıya ulaşır (Markides, 2008).

Özcan ve Barca (2008), işletmelerde yenilikçilik konusunu yeni ekonominin dinamiklerinde yatan bilgi temelli işletme tasarımları olarak açıklamıştır. Bilgi yönetimini destekleyen yönetsel süreçlerin etkin kurgulanması ve uygulanması, işletmelerde stratejik yönetimin merkezinde yer almaktadır. İşletme stratejilerinin pazarda rekabet gücü ve kazanma üzerine tasarlanması, bilgi temelli süreçlerin işletmelerde benimsenmesine bağlıdır (Özcan ve Barca, 2008).

Lafley ve Martin (2013)'e göre strateji, pazarda güç elde etmek için tercihte bulunma veya seçim yapma ile ilgilidir. Strateji kazanmak için tasarlanmalıdır. Bu yüzden, kazanma formülasyonu olarak seçeneklerin entegre bir yapısını ortaya 
koyarak işletmenin amacı (winning aspiration), oyun alanı (where to play), belirlenen oyun alanında kazanma metodu (how to win), yetenekleri (core capabilities) ve yönetim sistemi (management systems) gerekleri ortaya konulmuştur (Lafley ve Martin, 2013).

Strateji kazanmak için seçim yapmaksa yeni yatırım alanlarını belirlemek ve tercihte bulunmak için de strateji bir araç olarak kullanılmaktadır. Zook ve Allen (2010), karlı büyümenin hangi alanlardan geleceği sorusundan yola çıarak başlattıkları araştırmalarında işletmelerin temel işlerinin (core business) gerektirdiği yetenekler üzerine inşa edilen komşu alanlardan gelebileceğini iddia etmişlerdir (Zook, 2004; Zook ve Allen, 2010). Bu çerçevede, yeni karlı yatırımların işletme temel yetkinlik ve işlerine uygun olarak belirlenen alanlara yapılması gerekliliğini ortaya koyan komşu alan stratejisi sonraki bölümde derinlemesine incelenecek; başarı faktörleri örneklerle açıklanacaktır.

\section{Komşu Alan Stratejisi (Adjacency Strategy)}

İşletmelerin temel işinin (core business) etrafında birçok firsat bulunmaktadır. Komşu alan olarak tanımlanan esas işin radarındaki alanlar 6 temel tiple açıklanabilir (Zook, 2004).

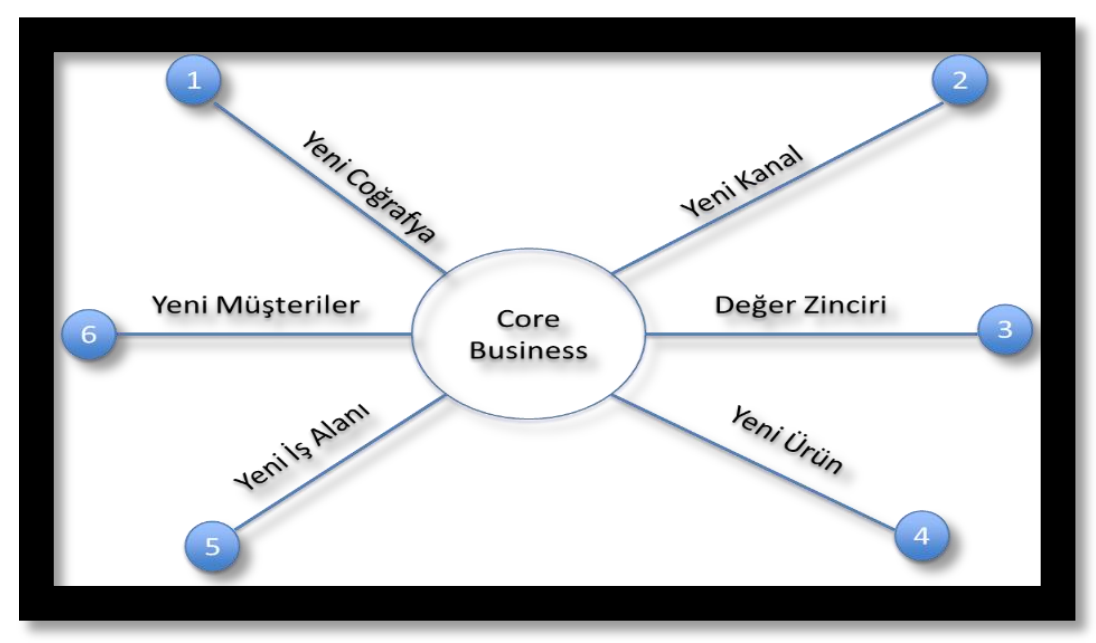

Şekil 2: Komşu Alan Tipleri (Zook, 2004)

Birincisi, coğrafi komşu alan (geographic adjacency) stratejisi, yeni coğrafya tanımlanarak firmanın yeni müşterilere hitap etmesidir. Uluslararasılaşmak isteyen tüm firmaların bu stratejiyi kullanması gerekmektedir. İkincisi, yeni kanal (channel adjacency) stratejisi, yenilikçi bir yöntemle yeni bir dağıtım kanalı ile ürünün müşteriye ulaştırılmasıdır. Örneğin, geleneksel perakende yönteminden internet üzerinden satış için yatırım yapmak bu alana örnek oluşturabilir. Üçüncüsü, değer zinciri komşu alan (value chain adjacency) stratejisi, değer 
zincirindeki ileri (satış, pazarlama) ve geri bağlantılı (hammadde vb.) faaliyetlerden bir veya birkaçına yatırım yapmaktır. Dördüncüsü, ürün komşu alan (product adjacency) stratejisi, müşterilere yeni ürün veya hizmet sunma olarak tanımlanmaktadır. Beşincisi, yeni iş alanı (new business adjacency) stratejisi, güçlü bir yetenek etrafında yeni iş modeli tanımlayarak ürün sunmaktır. Altıncısı ve sonuncusu olan yeni müşteri (new customer adjacency) ise yeni bir müşteri grubu için temel üründe değişiklikler yaparak karlılığı artırma çabasıdır. Lego oyuncak sektöründe müşteri segmentasyonu ile 2-5 yaş grubu için Lego Duplo ürünlerini ortaya çıkarmıştır (Zook, 2004; Robertson, 2013).

Karlı ve sürdürülebilir büyüme bütün işletmelerin amacıdır. Ancak bunu gerçekleştirebilen firma sayısı son derece azdır. Öyle ki, 1870 işletme üzerine yapılan çalışmada işletmelerin yalnızca yüzde 13'ü karlı büyümeyi gerçekleştirebilmiştir (Zook ve Allen, 2010). Karlı büyümeyi gerçekleştirebilmek için firmaların yeni ürünlere, pazarlara, dağıtım kanallarına, iş modellerine yatırım yaptıkları bilinmektedir. Örneğin, büyümek için komşu alan yatırımlarına önem veren $\mathrm{P} \& \mathrm{G}, \% 6$ büyüme gerçekleştirebilmek için 15 farklı komşu alan yatırımı öngörmektedir. $\mathrm{Bu}$ yatırımlar aynı zamanda rakiplere karşı giriş engeli yaratmaktadır (Lafley ve Martin, 2013). Ancak her yeni komşu alan yatırımı başarılı olamamaktadır. Başarılı komşu alan yatırımlarının ortak özellikleri sonraki bölümün konusunu teşkil etmektedir. Doğru tanımlanan esas işin yeni karlı alanlara uygulanabilmesi için iş modelinin tekrar edilebilirlik özelliğine odaklanmak gerekmektedir. Bu kapsamda, sonraki bölümün amacı bir komşu alan stratejisinde 4 başarı faktörünü örneklerle açıklamaktır.

\subsection{Güçlü Esas İş}

İşletmelerde temel işin iyi tanımlanması ve yeni alanların güçlü bir temel işten beslenmesi yeni karlı alanların tespiti için hayati önemdedir. Stratejinin temel başlangıç noktası, işletmelerde temel kabiliyetlerin ve yeteneklerin tespit edilmesidir (Hamel, 2000). İşletmelerin temel yetenek havuzunu ve yeteneğini tespit etmeden yeni yapılacak yatırımların temel iş uzmanlığına uygun olmayacağ düşünülmelidir. Örneğin, Sony’nin temel yeteneği minyatürleştirebilmek idiyse, Honda'nın temel yeteneği motor üretme üstünlügüüür. Bu kapsamda, temel yeteneğin doğru belirlenerek komşu alanlara tekrar edilebilir başarı formülleriyle aktarılması başlangıçta tanımlanan iş modelini başarılı kılar. Honda'nın motor üretme üstünlügüünun temel yetenek olarak tespit edilmesi, otomotiv sektöründen çim biçme makinesine kadar farklı alanlarda yatırım potansiyellerini de değerlendirebildiğini göstermektedir.

$\mathrm{Bu}$ noktada, Enterprise Rent-A-Car firmasının Şekil 3'teki gibi özetlenen genişleme stratejisine göz atmakta fayda görülmektedir. İşletmenin ana-temel işi araç kiralamadır. İşletme, bütün genişleme ve yatırım kararlarını bu temel iş üzerine kurgulamıştır. Sigorta kapsamında araç değiştirme ile başladığı iş hayatına, iş dünyası ve eğlence için araç kiralama, filo kiralama ve ikinci el araç 
satış pazarında da yerini alarak devam etmiştir. Söz konusu genişleme stratejisi aynı zamanda rakiplerin temel işe oluşturacağı tehditleri engelleme işlevi de görmektedir. Güçlü bir temel iş tanımı aynı zamanda ana müşterilerin de tanımını gerekli kılmaktadır. Şirketin sigorta kapsamında araç değiştirme işinin ana müşterileri tamirhaneler ve bayilerdir. Birinci temel yetkinlik, düşük maliyetli kent merkezi dışında müşteriye aracı kolay ulaştırabilme veya teslim etmedir. İkinci temel yetkinliği, yeni mezun insan kaynağının firmada işe başlatılması ve beceri setinin geliştirilmesidir. Üçüncü ve son temel yetkinliği ise en büyük araç filo hacmine sahip olmasıdır (Zook, 2004).

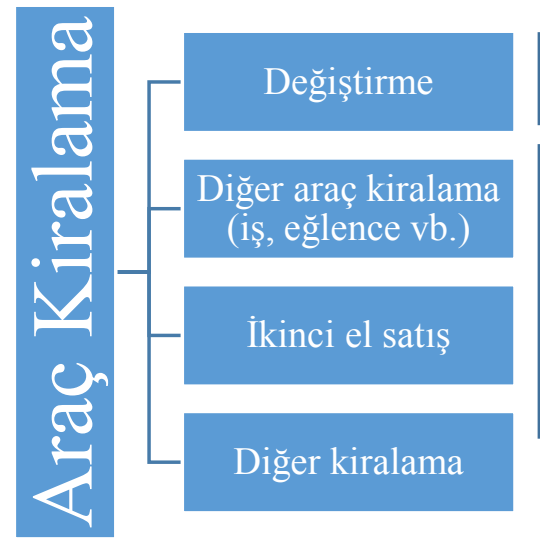

\section{Ana müşteriler: Tamirhane ve bayiler}

Temel yetkinlikler: Düşük maliyetli kent merkezi dışındaki networkler, insan kaynakları gücü ve en büyük filoya sahip olma

Şekil 3: Enterprise Rent-A-Car Komşu Alan Yatırımları (Zook, 2004)

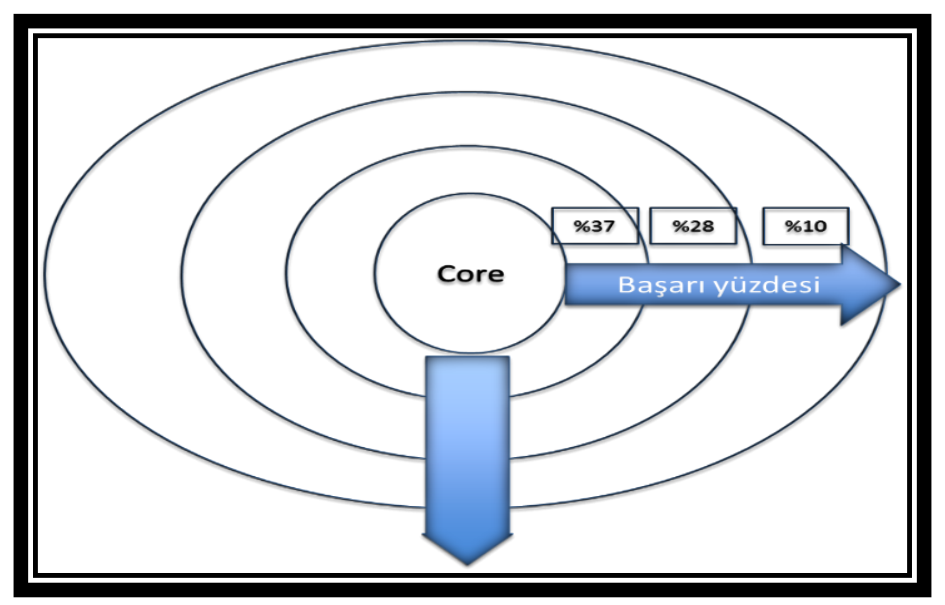

Şekil 4: Komşu Alan Başarı Yüzdesi (Zook, 2004)

Bain and Company tarafından yapılan çalışmaya göre işletmelerin temel işine en yakın alanlara yapılacak yatırımların başarı oranı \%37 iken en uzak alana yapılacak yatırımların başarı oranı \%10 ile sınırlıdır (Şekil 4: Zook ve Allen 2010). Esas işten uzaklığı değerlendirirken 5 temel soru göz önünde 
bulundurulmalıdır. Birincisi, müşteriler, yeni yatırım sonucu oluşacak ürün veya hizmetler bakımından farklılaşmakta mıdır? İkincisi, mevcut rakiplerden farklı bir rekabet içine mi girilmektedir? Üçüncüsü, maliyet yapısı aynı mıdır? Dördüncüsü, farklı dağıtım kanallarına ihtiyaç var mıdır? Beşincisi, farklı firma yeteneklerine ihtiyaç var mıdır? Söz konusu sorulara maksimum düzeyde verilecek "farklıdır" cevabı esas işten uzaklaşıldığını gösterecektir. İngiltere'de perakende sektöründe faaliyet gösteren 2 rakip firmanın, Tesco ve Sainsbury, komşu alan yatırımları güzel bir örnek teşkil etmektedir. Tesco, esas işe yakın eşsiz perakende modelini müşterileri merkeze koyarak oluşturmuştur. İş modelini koruyarak şehir dişında mağazalarına odaklanarak müşteri ve satışlarını artırmıştır. Bununla birlikte, Sainsbury, esas işini güçlendirmeden uluslararası yatırımları ile (örneğin Mısır'da yüzlerce perakende mağazası) başarısız bir büyüme politikası uygulamıştır. Tesco'nun Sainsbury'den farklı yaptığı iş, esas işini güçlendirmek ve esas işine uygun ürün sayısının artırılması (mağazada ecza ürünleri, mutfak ürünleri, kahve alanları vb.) yoluyla yeteneklerine uygun komşu alan yatırımlarını gerçekleştirmek olmuştur (Zook, 2004).

\subsection{Tekrarlanabilir Formül}

Tekrarlanabilirlik (repeatability) komşu alan stratejisinin başarısında dikkate alınması gereken ikinci unsurdur. Rekabet üstünlüğü sağlamak için farklılaşma stratejisine sahip şirketler; yeni alanlar, ürünler, pazarlar ararken mevcut iş modellerinin tekrarlanabilirlik özelliğine odaklanması gerekir. Bu noktada, tekrarlanabilir iş modelinde farklılaşmanın açıklanması faydalı olacaktır. İşletmede farklılaşma maliyet ekonomisi, eşsiz bir ürün özelliği veya ekosistemde anahtar bir kaynağa sahip olma şeklinde 3 temel yöntemle ortaya çıkabilir. İşletmelerin \%60'1 farklılaşmalarını maliyet ekonomisi yaratarak sağlamaktadır. Örneğin, Wal-Mart tedarik zinciri yönetimi yeteneği ile maliyet avantajına sahiptir. İşletmelerin \%30’u farklılaşma stratejilerini yeni bir ürün özelliği ile sağlamaktadır. Örneğin, Apple Ipad ile havayolu firmaları ise birinci sınıf (first class) hizmetleri ile müşterilerine özel deneyim sunduğu bilinmektedir. Son olarak, işletmelerin \%10'u ekosistem içindeki anahtar bir kaynağa sahiptir veya kontrol etme sürecindedir. Bu şekildeki farklılaşmaya örnek olarak şarj üniteleri için lityum kaynaklarına yatırım yapan firmalar gösterilebilir (Zook ve Allen, 2012).

İş modelinin komşu alanlara tekrarlanabilir özellikte uygulanması rekabet üstünlüğü yaratır. Nike ve Reebok komşu alan yatırımları yapan, 1990'da benzer gelire sahip iki şirkettir. 1990 yılında Nike faaliyet geliri 481 Milyon ABD doları iken, Reebok 300 Milyon ABD dolar gelire sahiptir. Her iki firmanın da esas işi sporcu ayakkabılarıdır. Nike komşu alan yatırımlarında net bir stratejiye ve tekrarlanabilir başarı formülüne sahipken, Reebok esas işinden uzak Boston Whaler bot firmasına yatırım yapmıştır. Ayrıca, Ralph Lauren ve Polo Footweat gibi markaları şirkete eklemeleri de esas işe uzak yatırım örnekleridir. Nike ise, 
1985 yılında Jordan hamlesi ile esas işini güçlendirmiş; 1990'larda ise basketbol, futbol, voleybol, golf gibi diğer spor alanlarında sporcu ayakkabısı alanında dominant piyasa oyuncusu olmuştur. Sporcu ayakkabısındaki başarı formülünü sporcu giyim alanına da aktaran Nike 106 milyar ABD doları piyasa değerine ulaşmıştır (Zook, 2004).

\subsection{Müşteriler}

Müşteriler, karlı ve sürdürülebilir büyüme isteyen tüm şirketlerin merkezindedir. Mevcut müşterilere sunulan mal ve hizmetlere yakın ilgili olan ürünler, hem mevcut müşterilere hem de yeni müşteriler için geliştirilmelidir. Müşteri segmentasyonu, büyümenin itici gücüdür (Lafley ve Martin, 2013). Örneğin İklimsa, Grenke işbirliğiyle yeni müşterileri cezbedebilmek için kiralama sistemini getirmiştir. Üründe herhangi farklılaşma yapmadan değer zincirindeki karlı alanı tespit ederek yeni müşteri segmentine hitap etmiştir.

\subsection{Kar Havuzu}

Kar havuzu, işletmenin içinde bulunduğu değer zincirindeki faaliyetlerin karlılık oranlarının analiz edilmesiyle ortaya çıkar (Zook ve Allen, 2012). Bu bakımdan, işletmeler, yatırım yapacakları alanları belirlerken yalnızca sektör analizi yaparak değil, değer zincirindeki karların kimler tarafindan ve nasıl gerçekleştirildiğini de önemsemelidir. Örneğin, otomotiv endüstrisi, imalattan pazarlamaya, ikinci el satışa, finansal hizmetlere akaryakıt satışına kadar pek çok değer zinciri faaliyetini barındırmaktadır. 1998 yılında yapılan bir araştırmaya göre, ABD otomotiv endüstrisinin satış gelirlerinin \%60’ı araç imalatı ve bayilik sisteminden geldiği ortaya koyulmuştur. Bununla birlikte, kar havuzu perspektifinden bakıldığında leasing (kiralama) faaliyeti en karlı alan olarak ortaya çıkmaktadır. (Gadiesh ve Gilbert, 1998).

\section{Kümelerde Komşu Alan Stratejisinin Dinamikleri}

Kümelenme birbiriyle bağlantılı olan işletmelerin ve kurumların belirli yerlerde coğrafi olarak yoğunlaşmalarıdır. Kümelenmeler, rekabet açısından önemli olan birbiriyle bağlantılı endüstrileri ve diğer kurumları içine alır (Porter, 1998). Kümelenme yapıları birden çok sektör ve firmayı kapsadığından ortak hareket kabiliyetinin avantajlarını yansitmaktadır. Bu yapılar, ortak bir vizyon etrafinda rekabet gücü kazanmak isteyen firmaların belirli bir iş planı dahilinde faaliyet zincirini uygulamak için bir arada hareket etme platformlarıdır. Tek başlarına belirli kapsam ve ölçeğe ulaşamayan firmalar için küresel ve bölgesel firsatlarını içinde barındırır. Şüphesiz ki ortak vizyona ulaşmak için bir kümenin etkin bir liderlik etrafında stratejiye sahip olması gerekmektedir. Söz konusu strateji, iş planı faaliyetlerinin bütçelenmesi, zamanlaması ve programlanmasından çok daha geniş yorumlanmalı ve yeni pazar, müşteri, ürün, süreç arayışında rakiplerden 
daha etkin bir düşünce yapısını içermelidir. Bu aşamada, kümenin sahip olduğu strateji dinamiklerini açıklamakta yarar görülmektedir.

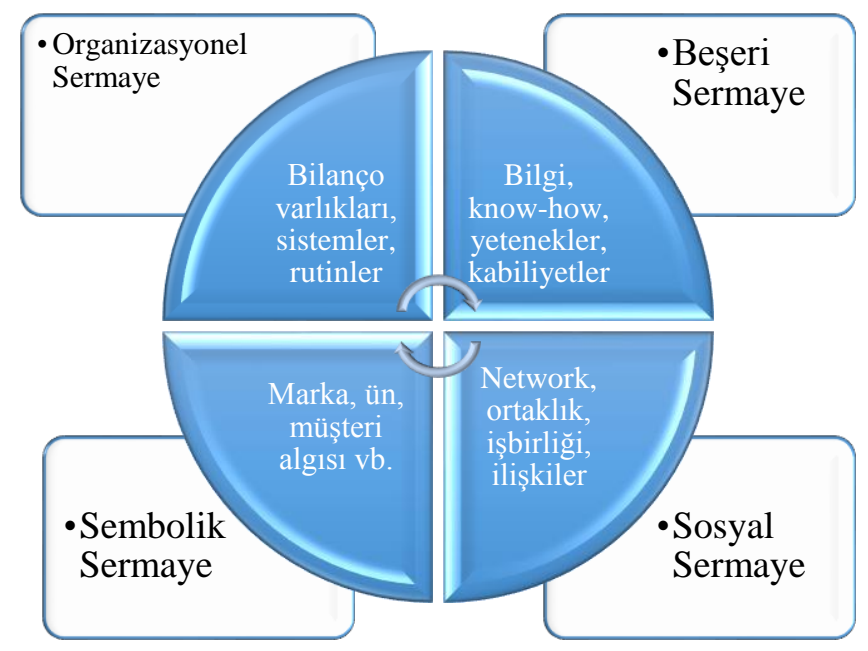

Şekil 5: Stratejinin Dinamikleri (Finkelstein, Harvey ve Lawton, 2007)

Kümeler belirli bir organizasyonel yapı içerisinde faaliyetlerini sürdürürken gelecekte olmak istenilen noktaya ulaşmak için komşu alan stratejisinin dinamiklerini tespit etmeleri gerekir. Başarılı bir strateji formülasyonu Şekil 5 'teki 4 sermaye tipinin etkin bir bileşimidir.

Organizasyonel sermaye, geleneksel sermayenin en tipik örneğidir. İşletme bilançosunda yer alan dönen ve duran varlıklar, işletme sistemleri ve günlük rutinler bu kapsamda değerlendirilir. Organizasyonel sermayeye yapılacak yatırım ölçek ve kapsam ekonomisi yaratır (Helfat vd., 2007).

Beşeri sermaye, organizasyondan ziyade kişilerin veya takımın bilgisini, beceri setini, know-how'unu, çalışanları motive gücünü dolayısıyla liderlik kavramını ifade eder. Beşeri sermayeye yatırım, daha iyi bir yönetim, verimlilik, aidiyet duygusu ve uzmanlaşmış iş gücü havuzu oluşturur. Beceri setinin geliştirilmesi firmaların katma değerli ürün yaratmada önceliğidir (Warner, 2004).

Sosyal sermaye, güven kavramından çok daha fazla anlam ifade eder. Her işletmenin bir ilişkiler ağı veya sistemi mevcuttur. Firma bu ilişkiler ağı veya tedarik zinciri ile diğer işletmelerle rekabet halindedir. Bu bakımdan, sosyal sermayeyi bir network, işbirliği ve ilişkiler ağı olarak tanımlamak gerekmektedir. İşletmenin tedarik zincirindeki faaliyetleri etkin ve verimli yöneterek kontrol etmesi veya tedarik/değer zincirine sahip olması rekabet avantajı getirir. Özellikle dijital ekonomide ilişkiler ağının kontrolü ve veriye hakim olma müşteri ihtiyaçlarının tespitinde bir adım öne geçmeyi sağlayacaktır (Viale ve Etzkowitz, 2010). 
Sembolik sermayenin organizasyonel sermayeye benzer olarak kurumsal bir boyutu vardır. Örneğin, büyük bir yatırımın arkasında kurumsal bir şirketin olması, diğer bir ifadeyle patronaj, sembolik sermayeyi ifade etmektedir. Marka bilinirliği ve ün, müşteri gözünde güven ve pozitif beklenti oluşturmaktadır. Markanın müşteri gözünde eşsiz bir yere sahip olması için kurumsal yönetim anlayışının işletmeye hakim olması gerekmektedir (Mathur ve Kenyon, 2001).

Söz konusu 4 sermaye birikiminin birbirini güçlendirici şekilde strateji uygulama aşamasında harekete geçirilmesi stratejinin başarısında önemli bir dönüm noktasıdır. Örneğin, 1983 yılında Leonard Bosack ve Sandy Lerner tarafindan San Francisco'da kurulan Cisco Systems firması başlangıçta üniversite için yerel networklerin haberleşmesi üzerine faaliyete geçmiştir. Küçük bir start-up olarak başlayan firmanın beşeri sermayesi yüksekti. Stanford Üniversitesi bağlantıları ve ilişkileri ile sosyal sermaye, ürünün satış grafiğini olumlu etkilemiştir. İki kurucunun da Stanford Üniversitesinden olması kişisel ün ve tanınmışlıklarını da artırmış, sembolik sermayenin şirket bünyesinde yer almasını sağlamıştır. İşletmenin en zayıf noktası organizasyonel sermaye eksikliğiydi. 1986 yılında şirketin \%30’u Sequoia Assoxiates girişim sermayesine 2.5 Milyon ABD dolarına satıldı ve profesyonel yönetim anlayışına geçildi. Cisco örneği strateji kurgulanmasında 4 sermayenin birbirini güçlendirici şekilde yer alması gerektiğini göstermektedir (Finkelstein, Harvey ve Lawton, 2007).

Cisco örneğinden de görüleceği üzere strateji dinamikleri işletme başarısında olduğu gibi kümelenme organizasyonlarının başarısında da hayati önemdedir. Kümelerin etkili platformlar ve arayüzler olabilmesi, 4 sermaye tipi çerçevesinde firmalara ne gibi katkılar sunacağına bağlıdır. Firmalar, ortak makine-ekipman, ortak hammadde alımları gibi organizasyonlarla bilanço varlıklarını artırarak küme içinde yer almanın avantajlarını organizasyonel sermaye sağlama suretiyle gerçekleştirmektedir. İşletmelerin kısa vadede gördüğü en temel fayda organizasyonel sermayeye yatırım yaparak ölçek ekonomisi yakalama hedefidir. $\mathrm{Bu}$ husus gerekli olmakla birlikte günümüz rekabet dünyasında yetersizdir. Yatırım yapılması gereken ikinci sermaye alanı beşeri sermayedir. İşletme bünyesinde çalışanların beceri setinin geliştirilmesi, inovasyon kapasitesini artıracağı için kümenin işletmelere sunacağı beşeri sermayeyi geliştirici hizmetler önemlidir. Küme içinde beceri setini geliştirecek ortaklıklar kurma, uluslararası işbirliği ve teknoloji transferi gibi yeni imkanların sağlanması, firmalara komşu alan yatırımlarını doğru tanımlamada ve uygulamada rekabet avantajı sağlayacaktır. Kümelenmenin firmalara sağladığı diğer bir fayda tedarik zincirindeki ilişkiler ve ağ yapılarıdır. Başarılı işletmeler esas işlerine yakın yeni komşu alanlara yatırım yaparken temel yetkinliklerine odaklanmaktadır. Örneğin IKEA'nın sağladığı uzun dönemli tedarikçi ilişkileri temel bir yetkinlik iken, diğer firmaların sahip olmadığı ağ yapısına sahiptir. Kümelenme yapılarının uzmanlaşmış tedarikçi ilişkilerini geliştirecek faaliyetler ile firmaların yeteneklerini geliştirici şekilde oluşturulması gerekmektedir. Sosyal sermayeye 
yatırım, firmalar arası güven ilişkisine de pozitif yansımaktadır. Yeterli sosyal sermaye yatırımı olmadan komşu alanlara sıçrama stratejisi etkin bir şekilde uygulanamayabilir. Kümeler ortak küme markası, marka bilinirliği, sofistike talep yaratma gibi faaliyetlerle firmaların sembolik sermayelerine de katkıda bulunmaktadır. Kümelere dahil olacak ekosistemin önemli oyuncuları olan prestijli üniversiteler ve diğer araştırma kurumları, iş yapma ve network kurma maliyetlerini minimize etmektedir. Cisco firmasının Stanford Üniversitesi ekosisteminden ve markasından faydalanması; kişisel bilinirliğine ve sürdürülebilir büyümesine katkıda bulunmuştur.

\section{Sonuç ve Öneriler}

$\mathrm{Bu}$ makalede, şirket ve kümelerin stratejik düşünüş ve stratejiyi ele alış biçimlerindeki yaklaşım farklılıkları ve buna bağlı olarak almış oldukları yatırım kararları ortaya konulmaya çalışılmıştır. Günümüz ekonomisine şekil veren en önemli değişiklik her şeyin artık çok daha hızlı değiştiğidir. Hızlı değişimin ve büyümenin yönetilmesi strateji ve rekabetçilik kavramlarını daha da önemli hale getirmektedir. Rekabetçilik ve strateji, bu hızlı değişim karşısında çok farklı tepkiler vererek kendini boyutlandırmaktadır. Bu kapsamda, stratejinin giderek artan bir önemde firma rekabet edebilirliğini artırma yolunda çözümler üreten bir mekanizmaya dönüştüğü olgusu da tüm dünyada kabul edilmektir. Bu nedenle, stratejik düşünmenin üst yönetimin işi olduğu geleneksel yargısına karşı stratejik düşünmenin bir kurumun tüm katmalarında olmazsa olmazı haline getirilmesi gerekmektedir.

Kümenin içindeki firmaların yeteneklerini ve uzmanlıklarını değerlendirerek büyüme amaçlı olarak farklı/komşu alanlara yönelmesi rekabetçiliğin artırılması açısından önemli bir kaynak olarak görülmelidir. Farkında olunmayan veya unutulan birçok kaynağın harekete geçirilmesi ve yeni oyun alanlarında sistematik bir mücadele, artan rekabet baskısı altındaki firmaların karlılıklarında daha kolay bir büyüme sağlayacaktır.

Küme komşu alan stratejisinde hareket etme yetisini elde ettiği takdirde bunu farklı alanlarda kullanma imkanına sahip olacaktır. Gelecek ekonomisinde ihtiyaçlara en hızlı cevap veren firmalar ve kümeler; yeteneklerini bu sürece uyumlaştıran ve tekrarlanabilir modeller üretebilenler olacaktır.

Başarılı bir stratejinin formülasyonu ise organizasyonel, beşeri, sosyal ve sembolik sermayenin etkileşiminden geçmektedir. Bu 4 tip sermaye kaynağından ihtiyaç duyulan sermayenin temin edilmesi rekabetçi bir stratejinin başarısında temel unsurlardan birini oluşturmalıdır. Bunun yanında her sermaye kaynağından elde edilen sermayenin değişimi ve bu değişikliklerin stratejiye olan etkisi sürekli olarak gözlemlenmelidir. 


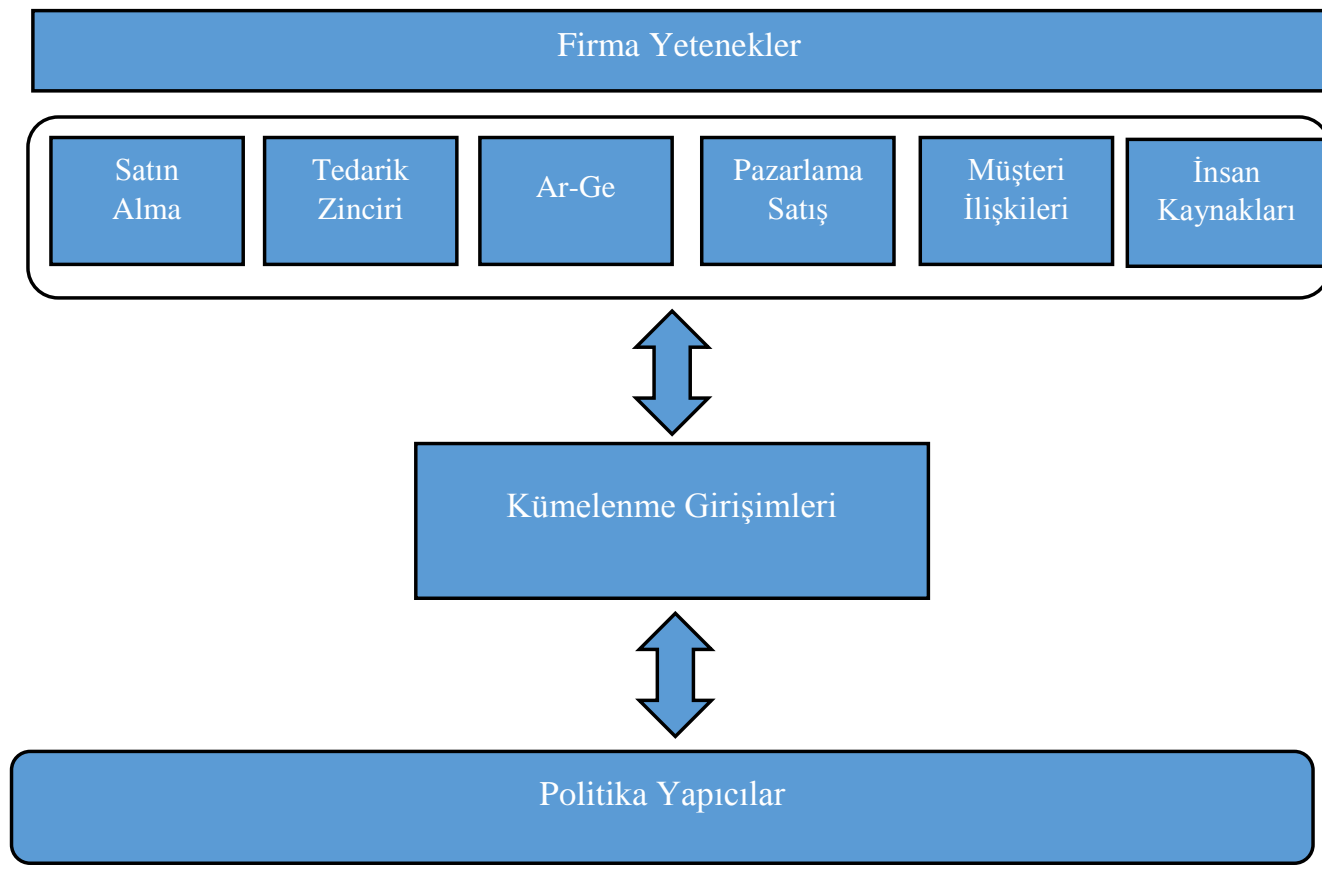

\section{Şekil 6: Kümelenme Girişimleri ve Yetenekler}

Kümelenme içinde yer alan işletmelerin kısa vadede gördüğü en temel fayda organizasyonel sermayeye yatırım yaparak ölçek ekonomisi yakalama hedefidir. Bu gerekli olmakla birlikte rekabetçiliğe ulaşma bağlamında yetersizdir. Kümenin orta vadede hedeflerine ulaşmayı sağlayacak en önemli nokta beşeri sermaye bağlamında elde edilen gelişmelerdir. Çoğu zaman bu hedef, organizasyonel sermaye elde ediniminin daha kolay olması ve bilançoya varlıkları artırma suretiyle hızlı yansıması sebebiyle göz ardı edilmektedir. Kümenin temel hedefinin, yeni bir oyun alanında firmaların bu alana göre şekillendirilmiş yetenekleri ile rekabet avantajı elde etmek olduğu unutulmamalıdır. Doğru bir küme stratejisi; organizasyonun temel yetkinliklerine ve stratejik yeteneklerine dayanır ve bunları etkin bir şekilde uygulamaya koyar (Barutçugil, 2013). Bu bağlamda gerekli beşeri sermayenin elde edilmesi hususunda politika yapıcılar için önemli bir tasarım alanı daha ortaya çıkmaktadır.

Politika yapıcılar, stratejinin dinamikleri olarak ifade edilen 4 tip sermayenin ekosistem içinde gelişmesini sağlayacak mekanizmalara ve politikalara odaklanmalıdır. Firma yeteneklerinin (satın alma, proje yönetimi, tedarik zinciri vb.) yeni ve karlı komşu alanlara sıçrama yapacak şekilde geliştirilmesi için kümelenme girişimleri arayüz olarak kullanmalıdır. Kümelenme girişimlerine verilen finansal destekler temel yeteneklerin organizasyonel sermaye ile ilgili olan bölümüyle ilgili olma eğilimindedir. Diğer bir ifadeyle, bilançodaki kısa veya uzun vadeli varlıklara (asset) yatırım olarak karşımıza çıkmaktadır. Ancak işletmenin mevcut bilanço varlıklarından ziyade bulunduğu ekosistemdeki 
(ecosystems) kuracağı ve yöneteceği ortaklık ve işbirlikleriyle gelecek ekonomisinin karlı alanlarını keşfetmesi beklenmelidir.

\section{Kaynakça}

Akman, G., Özkan C. ve Eriş, H. (2008). Strateji odaklılık ve firma stratejilerinin firma performansına etkisinin analizi, İstanbul Ticaret Üniversitesi Fen Bilimleri Dergisi, Y1l:7 Sayı:13 s.93-115.

Alparslan, A. M. ve Çarıkçı, İ. H. (2014). İşletmede strateji oluşturma yaklaşımlarını değerlendirmeye yönelik bir vaka çalışması, İstanbul Üniversitesi Işsletme İktisadı Enstitüsü Dergisi, Sayı 76.

Ansoff, H.I. (1965). Corporate strategy. NewYork: McGraw Hill.

Bakoğlu, R. ve Özcan, E. D. (2010). İşletme düzeyinde strateji paradokslarının mintzberg'in on stratejik yönetim okulu açısından değerlendirilmesi. Öneri, 9(34), (57-69.

Bartlett, C. A. ve Ghoshal, S. (1989). Managing across borders, Harvard Business School Press, Boston.

Barutçugil, İ. (2013). Stratejik yönetim, İstanbul: Kariyer Yayıncılık.

Berikol, B. Z. (2009). Maddi olmayan varlıkların ölçülerek maddi sonuçlara dönüştürülmesi: Strateji haritaları, Çukurova Üniversitesi IIIBF Dergisi, 13(2), 93-108.

Chandler, A.D. (1962). Strategy and structure: chapters in the history of the ındustrial enterprise. Cambridge: MA: MIT Press.

Finkelstein, S., Harvey, C. E. ve Lawton, C. T. (2007). Breakout strategy: Meeting the challenge of double-digit growth, New York: McGraw Hill.

Gadiesh, O. ve Gilbert, L. J.: Profit pools: A fresh look at strategy, Harvard Business Review, https://hbr.org/1998/05/profit-pools-a-fresh-look-atstrategy, 1998 (May-June Issue).

Grant, R.M. (1991). The resource based theory of competitive advantage: Implications for strategy formulation. California Management Review, 33(3), 114-135.

Grundy, T. (1994). Breakthrough strategies for growth, London: Pitman Publishing,. 
Grundy, T., Johnson, G. ve Scholes, K. (1998). Exploring strategic financial management, Prentice Hall.

Grundy, T. (2002). Shareholder value, Oxford:.Capstone Publishing.

Hamel, G. ve Prahalad, C. K. (1994). Competing for the Future, Boston: Harvard Business School Press.

Hamel, G. (2000). Leading the revolution: How to thrive in turbulent times by making ınnovation a way of life, Boston: Harvard Business School Press.

Helfat, C. E., Finkelstein, S., Mitchell, W., Peteraf, M. A., Singh H., Teece, D. J. ve Winter, S. G. (2007). Dynamic capabilities: Understanding strategic change in organizations, Blackwell Publishing.

Johnson, G., Scholes, K. ve Whittington, R. (2009). Fundamentals of strategy, Prentice Hall.

Johnson, M. W. (2010). Seizing the white space: Business model innovation for growth and renewal, Boston: Harvard Business School Publishing.

Kahveci, E. (2012). İşletme stratejileri ve ihracat performansı ilişkileri, Akademik Araştırmalar ve Çalışmalar Dergisi Yıl 4 - Sayı 6.

Kaplan, R.S. ve Norton, D.P. (1992). The balanced sorecard - measures that drive performance, Harvard Business Review, 70(1), 71-79.

Lafley, A. G. ve Martin, R. L. (2013). Playing to win: How strategy really works, Boston: Harvard Business Review Press.

Markides, C. C. (2008). Game-changing strategies: How to create new market space in established industries by breaking rules, San Francisco: JosseyBass.

Mathur, S. S. ve Kenyon, A. (2001). Creating value: Successful business strategies, Oxford: Butterwoth Heinaman.

Mintzberg, H. (1994). The rise and fall of strategic planning, London: Prentice Hall.

Özcan, K. ve Barca, M. (2008). Sanayiden bilgiye toplum, ekonomi ve işletmeler, Ankara: Siyasal Kitapevi.

Özşahin, M., Bayarçelik, E. B. ve Yıldız, B. (2017). Strateji tipleri ile yenlik performansı ilişkisinde stratejik karar verme hızının şartlı değişken 
(moderatör) etkisi, Uluslararası İktisadi ve İdari İncelemeler Dergisi, (16. UİK Özel Sayıs1): 749-766.

Papatya, G. (2017). rekabetçi strateji türleri ve işletme yetenekleri arasındaki ilişki: ankara ili merkezli ihracat işletmelerinde bir araştırma, Journal of Current Researches on Business and Economics, 7 (1), 1-16.

Peters, T. J. ve Waterman, R. H. (2004). In search of excellence: Lessons from America's best run companies, New York: Harper Collins.

Porter, M. E. (1980). Competitive strategy,.The Free Press, New York: Macmillan.

Porter, M. E. (1996). What is strategy? Harvard Business Review, 74(6), 61-78.

Porter, M. E. (1991). Towards a dynamic theory of strategy. Strategic Management Journal, 12(Special Issue: Fundamental Research Issues in Strategy and Economics), Winter, 95-117.

Porter, M. E. (1998). Clusters and the new economics of competition. Harvard Business Review, 77-90.

Robertson, C. D. (2013). Brick by Brick: How LEGO Rewrote the Rules of Innovation and Conquered the Global Toy Industry, New York: Crown Publishing,.

Sarvan, F., Arıcı, E. D., Özen, J., Özdemir, B., İçigen, E. T. (2003). On stratejik yönetim okulu: Biçimleşme okulunun bütünleştirici çerçevesi. Akdeniz. Üniversitesi İ.I.B.F. Dergisi , 3(6), 73-122.

Senge, P. M. (2006). The Fifth Discipline: The Art and Practice of the Learning Organization, Random House Business Books, London.Slywotzky, A. J. (1996). Value Migration, Harvard Business School Press, Boston.

Tanova, C. ve Karadal H. (2004). Kurumsal strateji ile insan kaynakları politikaları arasındaki ilişkinin analizi, D.E.Ü. I.I.B.F Dergisi, Cilt: 19 Sayı: 2 ss.123-136.

Ülgen, H. ve Mirze, K. (2007). Işsletmelerde stratejik yönetim, Arıkan Basım Yayın, İstanbul.

Viale, R. ve Etzkowitz, H. (2010). The capitalization of knowledge: A triple helix of university-industry-government, Edward Elgar Publishing, USA. 
Yıldırım, M. H. ve Çolak, E. E. H. (2016). Yurtdışına doğrudan yatırım yapan türk işletmelerinde strateji-yap1 ilişkisi. Aksaray Üniversitesi İktisadi ve İdari Bilimler Fakültesi Dergisi, 1 (1), 91-132.

Warner, R. (2004). How to run a thriving business: Strategies for success and satisfaction, Delta Printing, USA.

Zook, C. (2004). Beyond thec: Expand your market without abandoning your roots, Harvard Business Review.

Zook, C. ve Allen, J. (2010). Profit from the core: A return to growth in turbulent times, Harvard Business Review.

Zook, C. ve Allen, J. (2012). Repeatability: Build enduring businesses for a world of constant change, Harvard Business Review. 


\title{
Importance of Strategy in Firms and Clusters and Strategic Approach of Adjacency Move
}

\author{
Extended Abstract
}

\section{Introduction}

In today's world, companies are in search of various ways to grow and maintain their competitive position. They seek innovative investment opportunities to retain competitive advantage. However, many enterprises fail to turn investment and grow opportunities into a profitable business unit. The importance of the concept of strategy emerges in this process. The success of the growth strategies based on the core business and capability of the enterprises depends on their inability to invest away from the areas they are specialized in. It is a prerequisite for continuous value creation that new areas of investment and growth are with innovative business models in adjacency areas that are compatible with the core capabilities of enterprises. On strategy in Turkey, management school (Bakoğlu and Özcan, 2010), human resources policies (Tanova and Karadal, 2004), strategy maps (Berikol, 2009), the effect of strategy on firm performance (Akman et al., 2008; Alparslan and Çarıkçı, 2014), strategy types and innovation (Özşahin et al., 2017), the impact of business strategy on export performance (Kahveci, 2012), business capabilities (Daisy, 2017), the strategy-structure relationship in enterprises (Lightning and Colak, 2016) has taken place in various studies in the literature. However, no studies have been conducted on the interaction of capital dynamics with adjacency strategy to date. In this respect, the study contributes to the literature on the importance of adjacency moves in the strategic thinking of enterprises and clusters.

The main purpose of this article is to examine the historical evolution of the strategy, to find out the differences between the approach of the company and the clusters in the strategy, and to determine the interaction of the capital dynamics with the adjacency strategy.

\section{Method}

The fact that enterprises can sustain their profitable growth depends on their familiarity with the ecosystem they operate. By analyzing their ecosystems rather than traditional industry analyzes, firms find new investment opportunities in new and adjacency areas. In this sense, it is important to reveal and explain the strategy dynamics for the companies that want to leap into new areas. In this study, the concept of strategy is explained historically and the thesis put forward by the management gurus are discussed. The adjacency strategy is discussed in detail and the dynamics of the strategy are explained for cluster initiatives as well as enterprises.

\section{Results and Discussion}

A good definition of the core business in enterprises and new investment areas are vital for determination of new profitable business opportunities. The key starting point of the strategy is the identification of core capabilities and skills in enterprises (Hamel, 2000). It should be considered that new investments will not be suitable for basic business expertise without identifying the basic talent pool and talent of the enterprises. For example, if Sony's core capability is to miniaturize, Honda's core competence is its motor-producing superiority. In this context, the ability to determine the basic skills correctly and transfer it to the adjacency areas with repeatable success formulas makes the business model defined at the beginning successful. 
Companies increase their assets in balance sheet through joint machinery-equipment and common raw material procurement and realize the advantages of taking part in the cluster organizations by providing organizational capital. The second capital to be invested is human capital. Services that improve the human capital that the cluster will offer to businesses are important as it will enhance the skills set of the employees within the organization and increase the innovation capacity. Establishing partnerships to develop skill set in clusters, providing new opportunities such as international cooperation and technology transfer will provide competitive advantage in implementation and identification of new adjacency moves. Another benefit of clustering to companies is supply chain relations and network structures. Cluster organizations need to be developed in a way that enhances the capabilities of firms with activities that will develop specialized supplier relationships. Investment in social capital also positively affects the relationship between firms.

Evaluating the capabilities and expertise of the firms within the cluster and moving towards different / neighboring areas for growth should be seen as an important source for increasing competitiveness.

\section{Conclusion}

In this article, the differences between strategic thinking of firms and clusters and the investment decisions have been explained. The most important change that gives shape to today's economy is that everything changes now faster. Fast change and management of growth make the concepts of strategy and competitiveness even more important. Competitiveness and strategy have developed itself according to this rapid change in economic development. In this context, the fact that the strategy has become an increasingly important mechanism for enhancing the competitiveness level of the companies is to be accepted all over the world. Therefore, strategic thinking against the traditional approach that is business of top management needs to be taken place in all departments of the companies. 